\title{
An Analysis of the Role of Some Social and Individual Factors in Strengthening or Weakening Religious and National Identity (Case Study: Islamic Azad University of Tabriz and Azarshahr)
}

\author{
Kamran Pashaei Fakhri ${ }^{1}$, Parvaneh Adelzadeh ${ }^{2}$, Peyman Ghanimat ${ }^{3}$ \& Mohammadbagher Aali $^{4}$ \\ ${ }^{1}$ Department of Persian Literature and Foreign Languages, Tabriz Branch, Islamic Azad University, Tabriz, Iran \\ ${ }^{2}$ Department of Persian Literature and Foreign Language, Tabriz Branch, Islamic Azad University, Tabriz, Iran \\ ${ }^{3}$ Young Researchers club, Science and Research Branch, Islamic Azad University, Tabriz, East Azerbaijan, Iran \\ ${ }^{4}$ DBA student \& CEO of Hormozgan Cement Company, Iran \\ Correspondence: Kamran Pashaei Fakhri, Department of Persian Literature and Foreign Languages, Persian \\ Literature and Language Branch, Islamic Azad University of Tabriz, Tabriz, 5133638665, Iran. Tel: \\ 98-914-302-7053. E-mail: pashayikamran@yahoo.com
}

Received: January 17, 2012 Accepted: February 28, $2012 \quad$ Published: June 1, 2012

doi:10.5539/ijps.v4n2p278 URL: http://dx.doi.org/10.5539/ijps.v4n2p278

\begin{abstract}
Possessing an independent and distinguished identity in one's public and individual life is considered as a basic principle in his life as social relation. The element of recognizing, separating, and differing oneself from others gives meaning to his life and makes him be dynamic and mobile. Among various kinds of identities, religious and national one takes a special position among individuals' personality and their social and individual lives. From sociologists' point of views, the religious and national identity represents features making one society differ from another one.

In this research article (library and field study) through a survey based on Islamic Azad University of Tabriz and Azarshahr students with a statistical society of 1000 students and using valid sources and scientific methods, it has been tried to examine the role of minor variants such as career, family and etc for strengthening and weakening the religious and national identity specially among females and males.
\end{abstract}

Keywords: religious and national identity, career, family, education, weakening, strengthening

\section{Introduction}

Informing females and males about religion, culture and creating the right vision help them to preserve the religious and national identity and the Islamic values. They tend to follow models due to having special feelings and emotions belonging to adolescence period and they always look for finding proper models and imitating them. This should be paid attention, and a proper and right model should be presented to them so that transmission of destructive ideas and improper and vulgar models is stopped. Nowadays, it should be declared that the main origin of cultural aversion or weakening the religious and national identity among youth is caused by not knowing them, their sprits and the way to communicate with them. This reaction and inattention towards the religious identity is based on some beliefs and principles upon which this evaluation has been done and these evaluating principles and frames are established during various periods of personality formation in family and society. So it is not an offhand matter; however, it is a common thing resulted from some factors that have compiled over his life and led his tendencies and tensions to a special phenomena or matter like all his behaviors and deeds.

Social and human scholars believe to initiate social and human discussion, it should first be defined. Also, the suggested definition should have two universality and precision features. On the other hand, you should accept that defining human issues is a difficult and complex subject.

In Moein Persian Dictionary, the word identity means what results in identifying a person is the detailed truth i.e., whenever nature is considered and credited with person; it is called identity (Moein Dictionary 1992, 1223).

Ericson is one of the great psychologists who have paid much attention to "feeling identity". In his idea," identity is a feeling that one distinguishes himself from others and requires stability and consistency and recognizes 
himself as others' imagination of him. This imagination is a desired ideal and sometimes there is a problem in forming this feeling and imagining oneself. And one has no consistency (youth religion and national identity, 2004, 18).

Ericson calls it identity crisis or identity confusion. The author of Ethic Identity In Iran believes that "identity is a set of same fundamental social, cultural, psychological, philosophical, ornamental, and historical features and characteristics that expressively refers to group's nature or essence meaning unity similarity of the members, and consciously and clearly distinguish them from other groups and their members through within a specific time and place (Ethic Identity Crisis In Iran, 1999, 139)".

Identity consists of two individual and social dimensions. In the first one, it has been tried to answer these questions: who am I and what are my needs? What are my responsibilities towards others? What are others' responsibilities towards me? But apart from it, there is an identity in a higher and most common level in a general concept named public identity which means parts of social life where one applies the pronoun "we" to refer to that identity, and feels responsible towards it. Recognizing the social dimension of identity leads us towards the religious and national identity which is considered as one of the most important kinds of identity.

The national identity is the most universal but religious in all the social systems apart from "ideological approaches". The national identity is a process of a nation's conscious reply to questions about him, the past, quality, time, belonging, main and permanent origin, civilization, political, economic, and cultural position and important values of his historic identity (An Introduction to Iranian Culture and Management, 2005, 104). The national identity is a set of signs and material, biological, cultural and psychological works which distinguish societies from one another. For the signs and works differ from A to B.

In every society, different elements are involved in forming individuals' national identity such as language \& literature, society, friends' personality traits, moral principles, career, education, history, heritage and geography.

Furthermore, considering the religious discussion, having common religious teachings in a society is paid attention. Religion not only is an important factor in social relations in terms of function, it also causes encouragement, validity, cheer and common eagerness of individuals and integrated with national themes like government, history, and cultural heritage so that it would make societies different.

"Globalization" usually has two diverse effects on culture. It leads to cultural assimilation and unite different cultures. On the other hand, it leads to plurality heterogeneous and distinguishing cultures. This duality feature of globalization is also true about identity. Globalization both makes societies united by removing boundaries particularly in Islamic culture and causes cultural plurality by creating variety in the form of cultural identity (Globalization, 2010, 308).

Globalization has had the most shifts in individuals' especially Muslims' religious identification as most of the experts specially "Tabriz" regard it as a process of secularization.

Seyyed Reza Ameli, an Iranian researcher and sociologist, offers his septet typology inspired by Castlerz typology:

* The nationalist identity: valuing norms and national values

* The traditional identity of norms and religious values

* The Islamic identity: Islamic norms and values

* The modern identity: integration of tradition and modernity

* The secular identity: separation of religion from politic and economy

* The synthetic identity: lack of a privileged and specified identity and mainly formed from traditional belongings and a new circumstance in which one lives

* The uncertain identity: it mainly includes young people who have no tendency towards a special identity in terms of tradition or modernity

According to the main characteristics of globalization such as compress, time and place, swift communications, speed of the changes, co-existence of universality and particularity, spread of religious and cultural diversities, change in the cognitive dimensions and defenseless and rootless and etc, it can be imagined that in this condition, the relation between understanding, action and religious beliefs and also social relations have been weakened because of variety of religious understanding and plurality of religion, and tendency towards secular identity is confirmed and reinforced.

Therefore, globalization particularly by weakening the relation between understanding, action and religious 
beliefs, as an introduction to the creation of religious identity, results in the advent of doubtful identity (not modern nor traditional), then the mixed identity with traditional ciliate belongings and new environment for life and finally the secular identity, which causes the separation of religion and politic. The separation of religion from politic with the emergence of secular identity, the role of religious teachings for individual in the society as a comprehensive measure of value has been weak, minimized or ineffective.

Mehdi Sajjadi, the Iranian sociologist, calls "promotion of the material-oriented ideas, uncertainty of beliefs, instability of family foundation, secularization and emphasize on secular teaching, conflicts between religious teachings and belief in wisdom as educational implications of modernism (General Culture and Objective Education, version No. 29, 2380)."

From some sociologists' points of view, to neutralize or weaken the effects of globalization, two things should be followed:

1- Different positions and situations should be identified and analyzed typically there are three types of positions: "resistance and opposition; submission and inaction, proper but critical interact with the phenomenon of globalization i.e. getting the positive elements and criticizing the negative ones.

2- Confirming the third position and acting accordingly, there should be creativity and initiatives so that the present social conditions have the least effects on religious teachings and the role of religion in model code into society. Generally, three types of innovation should be considered in this regard.

a- innovation at the transnational level: globalization should be considered as objective and subject-oriented, and purposeful meaning and leading this global project should be taken into account.

b- innovation at the national level: in this regard, globalization should be considered as a natural process, thus, special training programs should be planned for the society.

c- innovation at the individual level: enforcing the internal values and emphasizing on the internal bonds on the basis of escaping the pressure caused by education affected by the globalization culture (Explanation of the Relationship between Globalization and Objective Training, 2009, 1110-1140).

In this library and field research, the main and primary question is that if religious identity among male and female students has been weakened and why?

c-1- is the society influential in youth withdrawal from national religious identity?

c-2- Is there any relation between one's awareness national identity and his withdrawal from national and religious one?

c-3- Are the officials and managers influential in youth' withdrawal from national and religious identity?

c-4- Can one's career influence his withdrawal from national and religious identity?

c-5- Can parents' careers influence one's withdrawal from religious and national identity?

c-6- Is there any relation between one's education and his withdrawal from religious and national identity?

c-7- Is there any relation between parents' education and one's withdrawal from religious and national identity?

c-8- Is there any relation between personality models and one's friends and weakening the national and religious identity?

c-9- Does the media (local and foreign) affect youth' withdrawal from religious and national identity?

\section{Research Purposes}

General purpose: to evaluate the effective factors weakening or strengthening religious and national identity.

Special purpose: The mere objective of this study is to know the main nation causing the suffering reasons in society and offering appropriate strategies to deal effectively with. Since the youth are always considered as the future maker in any community and have allocated a large percentage of the population, they should grow in the best possible way and receive useful and effective education. Also, officials and prop rammers should know about the problems specific to each group and offer a proper solution to deal with them, for we all believe that facing every problem and corruption radically and practically is the most effective way. Informing people using advertising agencies should be through the same proper and satisfactory method and the same template that values are explained so that youth are notified about what is to happen against them. You should accept the fact that educational equipments have a special inductive power which can be both an irritant and a social unity offering programs about treating youth rationally, non-coercion and strictness, cooperation and coordination sociological, psychological, educational and communicational issue can be very effective. Thus according to the 
dramatic influence of mass media, using several human senses simultaneously, one can benefit much offering solutions. You should think of a choice, which make us understand the reasons deeply and other hand, it should be far from the slogans that are not based on any ontological foundation. And this wont be possible unless we can be in a free environment where thought can travel, have critical thinking and also the generous can stand criticism much. It requires intellectual maturity along with what is called tolerance. And in Islamic teaching, it is called tolerance for criticism and flexibility against them. Its solution is to refer to thinker. So, they should be on sided and complementary and doubtful and misleading cases should be avoided. Meanwhile inner thought and belief should be given chances to rise. In a short run, this might result in misery and thoughts "unrest and tension", but in a long run, it results in intellectual maturity, strong deduction and analysis in all the societies. And that cultural ideology can remain forever to respond questions and ambiguities raised.

Techniques of practical and subtle advertisement are to change thoughts and beliefs. A psychological practice tries to convince the audience to his speech by combining various mental emotional factors and appropriate advertising. It should be noted that a preacher can not create anything in vacuum or be successful in any situation and time. For a preacher is effective in action, he needs a stage to create context and provide the spirit of acceptance in the addressee, he should know the environment, and consider the cultures and values dominant in the society and establish his action in the fields that are widely accepted in society.

Leaving responsibilities to youth to reach self- confidence is very important. Because without serious and deep attention to youth (facilities and emotional acceptance), they are not expected to have positive, cooperative and constructive behaviors.

Introducing prominent scientific political, religious, figures, improving mass media specially in case of offering programs about religious and national identity, qualitative reconstructing of schools and universities, enriching the scientific and cultural condition of youth is of particular importance.

Youth' physical confrontation and collision is a pill which relieves the pain temporarily and gives rise to the temporary and unstable feeling, but it is not a viricide and does not remove the pain completely. Poverty is one of the reasons for youth to be unrestrained. So the Islamic government should think about providing social and economic justice in society, which consequently will strengthen the society's religious and national identity.

This issue can not and should not be passed except by the educated people and in this case, new emotional workforces should not be hired; otherwise, it is grown more complicated and get worst.

In this part, some educational implications of modernism and post-modernism are mentioned:

Here is the summary of some young females' points of view about the reasons for weakening the religious identity among some youth with a statistical population of 500 people: lack of understanding the importance of this identity and its effects on social, private and international life, not introducing the religion of Islam well, youth commitments to religious and national noble identity are some reasons that mass media can help to eliminate them through proper planning.

Also, lack of familiarity with the rich religious culture, a significant gap between parents and children, lack of necessary knowledge transferring in all fields of life issues that inevitably children will be faced with someday, commitment to ethic, an unrestrained society, lack of publicity and mass media's informing about religious identity, lack of appropriate model in the family, different social opportunities, lack of maturity, parents' ignorance the religious and national identity, unfamiliarity of most youth with the importance of religious identity due to some false and mandatory advertising, widespread increase of hypocrisy, presence of people who seemingly religious but the effects of religion are not apparent in their actions and regard themselves right and if they find something against them, they may violate Islam and others' rights. Uncertainty of boundaries between good and evil, shortage of time, disappointment with the world, relationship with unsafe people, too much publicities in society, acting as believers, doing everything in the name of faith.

Young males' points of view about the reasons for weakening religious and national identity among some youth with a statistical population of 500 people:

Lack of spiritual comfort and life turbulence, inappropriate interference of various social group about youth' beliefs and faith, cultural invasion, poor role of government and officials in a basic planning, increase in the number of aggressive scholars, lack of actions of missionaries to their own words, lack of progress of scientific, religious, cultural and social purposes, lack of proper environment to encourage youth, inconsistency of authorities and clergy's remarks, apparent advances of secular society.

Placement of heterogeneous situation among people and improper contacts about legal questions, creation of negative attitudes through improper contacts, lack of commitment to the principles of belief and faith, less 
freedom for youth. Lack of Islam's, Koran's and real religion's view, which was previously evident in books and media, observation of another Islam as a factor having been in the hand of jobber people, doing everything with the name of coercion and imposition of idea, too much rummeving about religious principles, lack of trust and confidence in their leaders, spread of corruption due to lack of strategies for proper management.

Lack of proper training in childhood, negative publicity, lack of proper knowledge, lack of detection of the effects of commitment to religious identity among some worshipers, too much publicity about religious without the correct logic, differences in values, lack of knowledge of the spirit of this identity, lack of awareness and enough knowledge about the real meaning of praying(Salat) and the reason for that, being influence with western issue, existence of anti-religious in society and adverse publicity among individuals, inappropriate (unsafe) friends, weak inner belief, and lack of correct understanding about the existence of God, family's wrong training,

Society's atmosphere: there are various deviant and anti-ethic issues which have adverse effects on individual's religious beliefs.

Unemployment: when a young man is working, he will never think of deviant issues.

Inappropriate publicity of Islam: Islam is not the one being advocated in media or public. It is the religion of freedom, love of God and living cheerfully unlike the dominant Islam in the society.

Hypocritical missionaries: when one is encountered with a person who is unqualified but admonishing fellow believers to do right and to avoid sin, he is discouraged.

Increasing stress and the resulted depression is nicely explained by Hafez (an Iranian poet) as follow:

Preachers teaching in alter and pulpit

Act differently when alone

A question of mine should be answered

Why repent themselves repent less?

\section{Academic staff's points of view about it with the statistical population of 50 people:}

One of the main concerns in psychology is that everyone has some needs and to meet them, he particularly needs to try. As human needs are removed according to their importance, he looks for solving other problems. Overcoming the need for hunger is more important. If it is not removed, no physical body is left. Also, as long as there is no safety, one never tends to reveal his talents and creativity. Religion is also the element of meeting need for security provided that one understands religion and its real meaning.

The real religion and praying which has been called believers' ascension according to the Prophet Muhammad (PBUH) should be taught to youth and make them understand that praying puts them into a strange spiritual status. Unfortunately, our youth pray according to a habit or by the insistence of their parents or elderly people. From the author's point of view, the reason for the weakness of some youth may be lack of knowledge about the truth beyond religion and God.

In another word, understanding will be the only basis and essence of love to religious identity and it is a wrong illusion that whoever is literate, an engineer or a physician disbelieves in God. No, it is not like that. The more knowledge one has, the more manifested God is in his life. For real religion is nothing but science and the meaning of Islam is the very understanding of realities.

A pious always seeks for understanding the reality beyond creatures.

If a researcher studies non- praying individuals, he will find most of them unaware of the fact of creation or aware but following vagary and laziness. Immam Ali in his book Nahjolbalagheh states:

No knowledge and cognition happens except by practicing, whoever gains knowledge is led to practice and whoever does not gain any will have no practicing.

If education means perfection and much understanding, religion will gain greater importance. Because having religious identity brings consistency and stability for human society, and removes all chaos from society; besides, it will cause individuals' spiritual and psychological security.

God has entrusted religion to youth and no one dares to say that somebody is infidel and ungodly. It is the same divine bond which is up to parents and rulers. Weakening this identity is caused by society's normal and abnormal behaviors including unemployment, lack of safe environment, lack of public parks, lack of motivation of officials and lack of access to peaceful and attractive places, lack of expertise in religious and political issues.

Every task has its own way and principles and if one does not go through it, he will face problems for sure. 
Dr. Shariati says: to destroy the truth, never attack it well, but defend it badly.

Sometimes lack of reasonable and proper reasons for issues make problem complicated which will leave its effects.

Dr Behshti says: Islam has power of attraction in a premium possible limit and repulsion in essential in essential limit. In fact, this is unlike what is dominant in our society. For, no prescription is the same for all. Capacities and age are important. Capacities and age is important. Individual and psychological differences are important. There is a difference between the "I" in our ID card and rational "I" which should be taken into account. It should be clear who he is, and what treatment is proper for him. Methods must be measured.

\section{Research Results}

The result of a survey among 1000 youth in Islamic Azad University of Tabriz and Azarshahr is as follow:

\section{Influential factors in enhancing the religious and national identity:}

1. Society $92 \%$

2. Personal traits and friends: $86.5 \%$

3. Hypocrisy: $84 \%$

4. Being unfamiliar with Islam and its laws: $81.5 \%$

5. Lack of commitment to ethical principles and state officials and managers' practices each: $81 \%$

6. Individuals' awareness of national, culture and mass media each: $75 \%$

7. Career: $48 \%$ and unemployment $18 \%$

8. Gender $45.5 \%$, male $35 \%$ and female $9 \%$

9. Parents' career: $44.5 \%$

10. Individual's education $41.5 \%$, lack of education: $21 \%$

11. Parents' education $33.5 \%$

\section{References}

Ahmad Saboori (2003). Social course. Child. K,. Tehran, Neil press.

Ali Altayi. (1999). Ethnic Identity Crisis in Iran. Shadegan press.

Allameh Abdolhossein, Alamini (2006). Alghadir. Tehran, DarolkotobolEslamiyeh.

Asghari Khanghah (2010). Bio-anthropology. SAMT

Bahaeldin Khoramshahi (2006). Hafiz Divan (7th Ed.). ElmiFarhanhi press,Tehran.

Bahaeldin Khoramshahi (2008). Holy Quran. Tehran, Jami and Niloofar press.

Baharom (2004). Some issues in culture of Iran. Tehran, Fekr-e-rooz press.

Hamdi Enaiet (2008). Politics of Aristotle. Tehran, Neil press.

Jalaleldin Mohammad Rumi (2009). MasnaviManavi (1st ed.). Tehran, Rastin press.

Maryam Manba Ejlal (2005). An Introduction to Iranian Culture and Management. Publications of national research development.

Mehdi Sajadi (2005). General Culture and Objective Education, version No. 29.

Mohammad Akhundi (2004). Youth Religion and National Identity. Ghom press.

Mohammad HosseinIbn Mousa Seyyed Razi (1415 L. H). Nahjol-balagheh. Research by Dr. SobhiSaleh, Beirut. Darolosveh.

Mohammad Moein (1992). Moein Dictionary. AmirKabir press.

Naser Fakoohi (2003). The history of ideas and anthropological theories. Ney press, Tehran.

Rashed Mohassel (2010). Rescue in religions. M.T. Tehran. Cultural studies and researches.

Saeed Reza Aameli (2010). Globalization.

Shapoor Rasekh (2001). Education in the present world (3rd ed.). Tehran. Amirkabir press.

Sheikh Toosi AbiJafarIan Hassan Toosi (1984). Alestebsar. 460 L.H Tehran. DarolkotobolEslamieh. 
Siavash Pourtahmasebi (2009). Explanation of the Relationship between Globalization and Objective Training. 